\title{
GLOBAL VS. GROUP-SPECIFIC BUSINESS CYCLES: THE IMPORTANCE OF DEFINING THE GROUPS
}

\author{
Tino Berger and Marcus WortmanN \\ Georg-August-University Göttingen
}

The literature on international business cycles has employed dynamic factor models (DFMs) to disentangle global from group-specific and national factors in countries' macroeconomic aggregates. Therefore, the countries have simply been classified ex ante as belonging to the same region or the same level of development. This paper estimates a DFM for a sample of 106 countries and three variables (output, consumption, investment) over the period 1960-2014, in which the countries are classified according to the outcome of a cluster analysis. By comparing the results with those obtained by the previous grouping approaches, we show substantial deviations in the importance of global and group-specific factors. Remarkably, when the groups are defined properly, the "global business cycle" accounts for only a very small fraction of macroeconomic fluctuations, most evidently in the industrialized world. The group-specific factors, on the other hand, play a much greater role for national business cycles than previously thought-also in the pre-globalization period.

Keywords: International Business Cycles, Globalization, Regionalization, Dynamic Factor Models, Cluster Analysis

\section{INTRODUCTION}

The globalization of trade and financial linkages over the past decades coincided with many regional and group-specific integration processes affecting countries' economic developments to varying degrees. As the severity and recovery time of globally experienced shocks have differed more significantly across such country groups since the financial crisis of 2008/2009, one might expect a shift in the relative importance of international factors for domestic business cycles. To quantify each country's vulnerability to foreign developments on different levels, the empirical literature has decomposed national macroeconomic fluctuations into global, group-specific, and country-specific factors using large-scale dynamic factor models (DFMs). An important aspect of this empirical literature is that there is still a controversy regarding the relevance of a global factor governing local business cycles. 
The seminal work of Kose et al. (2003) found evidence of a "global business cycle" dominating the importance of seven regional cycles when conducting a DFM with 60 countries and three macroeconomic aggregates over the period 1960-1990. However, Helbling et al. (2007) repeated this exercise with an enlarged database of 90 countries in the period from 1960 to 2005 and found the relevance of the global cycle to have declined in the later part, while regional shocks have become more important, especially in North America (NA), Europe, and Asia. The growing importance of regional factors relative to the global factor is underlined by Mumtaz et al. (2011), who conducted a DFM with output and inflation rates for 36 countries over more than 75 years. Based on an extended dataset of 23 industrialized economies (IEs), 24 emerging markets (EMs), and 59 developing countries (DCs) covering the period 1960-2008, Kose et al. (2012) found that the global business cycle has become less relevant for the IEs and EMs since the "globalization era" starting in the mid-1980s. On the other hand, the group-specific factors have henceforth gained importance for these country groups, indicating a "decoupling" of countries from the global business cycle. By partitioning this data of 106 countries into seven regions, Hirata et al. (2013) amend the previous results, stating that "the recent era of globalization has witnessed the emergence of regional business cycles." Ductor and Leiva-Leon (2016), conversely, show with their time-varying DFM that the sensitivity of most EMs' business cycles to the global factor has rather increased over recent times.

In sum, this empirical literature provides very mixed evidence regarding the importance of a global business cycle for domestic macroeconomic aggregates. This result may in part be explained by the different modeling of the regional and/or group-specific factors. In fact, a crucial limitation of the studies listed above is that the group-specific factors are statically modeled as either common to the countries of a particular world region [Kose et al. (2003), Hirata et al. (2013)] or at the same level of development [Kose et al. (2012)]. The underlying group compositions are set ex ante and, in the latter case, do not account for any time variation over the pre- and the globalization periods considered. By doing so, the applied DFM will only verify the potential role played by very specific common factors suspected to permanently exist in any of these country groups. If, however, the continually changing trade linkages have rather entailed cyclical interdependencies among country groups of different shapes or even within smaller subgroups, the importance of any pre-specified group factor for domestic cycles may be significantly misinterpreted. Imagine, for example, the suspected "European business cycle" is found to exhibit only weak explanatory power compared with the "global business cycle" for all the European countries [Kose et al. (2003)], this may simply hide the fact that some countries (like, e.g., the UK and Ireland) may rather belong to a transatlantic cluster together with the USA and Canada and that the DFM should thus account for two distinct group-specific factors, one Central European and one inter-regional Anglo-Saxon. In fact, this is what the following analysis will document. 
The only paper considering this problem of DFM is that of Francis et al. (2017), stressing indeed that imposing factors in a DFM, that are not in the data implies a misspecification and may lead to factor estimates and hence variance decompositions that deviate substantially from the true model. Francis et al. (2017) determine the number and the composition of the groups endogenously based on series-level covariates. ${ }^{1}$ In fact, the "optimal" groups found by their approach do not correspond to the seven regions of the world presumed by Kose et al. (2003), and there are significant differences in the resulting variance decompositions, too. When they estimate their DFM based on three endogenously classified country groups, the group-specific factors explain, on average, about $23 \%$ of macroeconomic fluctuations, compared with less than $3 \%$ found by Kose et al. (2003). The comparability of such results, however, is limited, because different from the study of Kose et al. (2003), only Gross Domestic Product (GDP) data for 60 countries were used and, hence, no country factors were estimated. This extension is left for future research by the authors and therefore considered in the present paper. Moreover, their clustering of countries is based on "covariate data," limiting the applicability for larger global datasets and thus requiring a different grouping approach. To cope with this problem, we conduct a hierarchical cluster analysis that reveals the business cycle data-inherent grouping structure before estimating a DFM. This two-step approach does not require any more variables than those used in the DFM and therefore allows us to analyze large-scale datasets.

In particular, the present paper adds to the literature by assessing the relevance of the global and the group-specific factors when the original DFM designed by Kose et al. (2003, 2012) is applied to the same (time-extended) global dataset of 106 countries and three macroeconomic aggregates and the number of groups as well as their compositions are varied. Thereby, the variance decompositions arising from the DFM based on the pre-specified groupings supposed by Kose et al. (2012) and Hirata et al. (2013) are directly compared with those for which the grouping pattern has been drawn from the cluster analysis. This approach is not only independent from "covariates" but provides direct insights into the hierarchical country group pattern of global business cycles, proving the existence of any business cycle cluster rather than assuming it beforehand. Moreover, as such group pattern is likely to have changed over time, we additionally estimate the DFM for the pre- and the globalization periods using the respective databased grouping structures in order to gain a better understanding of the previously detected "decoupling" and "regionalization" trends.

The main findings can be summarized as follows. The formerly used regional as well as the development-based ex ante country groupings are found inaccurate, most evidently for the pre-globalization period. By contrast, the data-based grouping is a mix of both, with regional cyclical similarities most dominant in Central Europe, South East Asia, parts of Latin America but, otherwise, often limited to some direct neighbor countries. An Anglo-Saxon cluster rather provides evidence of inter-regional cyclical linkages resulting most likely from historical connections between these countries. The formerly used grouping based on the levels of 
development is most apparent between most IEs of the sample and all the other countries, of which the EMs and DEs should not be separated accordingly.

When the DFM is estimated based on the underlying cyclical similarities revealed by the cluster analysis, the relevance of the group-specific factors is found to be much higher than that based on the previously used groupings. On the other hand, the contribution of the global factor becomes, on average, negligible and very much limited to the IEs. The deviations in the relative importance of these two factors are found to be even more substantial for individual country groups like the G-7, USA/CAN, and the EU-12.

Despite finding evidence in support of the regionalization trend and the decoupling hypothesis (growing importance of intragroup factors, declining relevance of the global factor over time), we show that, when the groups have been defined properly, the group-specific factors already exhibit almost equal importance as the global factor in the pre-globalization period. This indicates-in line with our findings from the cluster analysis - that the country groups previously supposed by Kose et al. (2012) and Hirata et al. (2013) simply did not exist at least before the mid-1980s, resulting in an incorrect estimate of the relative contribution of the global and the group-specific factors in these studies.

The remainder of this paper is organized as follows. Section 2 introduces the DFM and the clustering method that we employ as well as the dataset. The results of the cluster analysis and those of the DFM due to the different country group specifications are presented in Section 3 for the full sample period. We also assess the implications for the "decoupling" and "regionalization" notions by conducting the DFM for the two subperiods using the respective data-based grouping structure. In Section 4, we draw some conclusions.

\section{METHODOLOGY AND DATA}

\subsection{The Model}

Consider a hierarchical DFM with multiple observed variables per country and multiple unobserved factors similar to Kose et al. (2003, 2012). More specifically, our factor model contains a global factor common to all variables in all countries denoted by $F_{t}^{\text {Global }}$, group-specific factors that are common to all countries and variables in a given group of countries denoted by $F_{t, j}^{\text {Group }}$, and country-specific factors, $F_{t, k}$ common to all variables in country $k$. The DFM takes the form,

$$
\begin{aligned}
y_{i, t}= & \alpha_{i} F_{t}^{\mathrm{Global}}+\sum_{j=1}^{M} \beta_{i, j} F_{t, j}^{\mathrm{Group}}+\sum_{k=1}^{N} \gamma_{i, k} F_{t, k}^{\text {Country }} \\
& +\mu_{i, t}, i=1, \ldots, K \times N, t=1, \ldots, T
\end{aligned}
$$

where $M$ denotes the number of groups, $N$ is the number of countries, and $K$ denotes the variables per country. Each observed variable $\mu_{i, t}$ is explained by the global factor with loading $\alpha_{i}$, by a group-specific factor with loading $\beta_{i, j}$, by its 
country factor with loading $\gamma_{i, k}$, and an idiosyncratic component $\mu_{i, t}$. As is common in the literature on the international business cycle, we impose a hierarchical structure, that is, all countries and variables load on the global factor but each country only belongs to one group. As a consequence, some loadings in $\beta_{i, j}$ and $\gamma_{i, k}$ are restricted to be equal to zero, as the observed variables do not load on every group and country factor.

The model is completed by assuming stochastic laws of motion for all unobserved factors. Following Kose et al. (2003, 2012), we assume all factors in eq. (1) to follow zero-mean $A R(3)$ processes,

$$
F_{t}^{V}=\sum_{l=1}^{3} F_{t-l}^{V}+\varphi_{t}^{V}, \varphi_{t}^{V} \sim \operatorname{iid} N\left(0, \sigma_{\varphi^{V}}^{2}\right),
$$

for $V=1+M+N$. Similarly, all idiosyncratic components are assumed to follow zero-mean $A R(3)$ processes,

$$
\mu_{i, t}=\sum_{l=1}^{3} \mu_{i, t}+\varepsilon_{t}, \varepsilon_{t} \sim \operatorname{iid} N\left(0, \sigma_{\varepsilon}^{2}\right) .
$$

As it stands, the model given by eqs. (1)-(3) is not identified without further restrictions as neither the signs nor the scales of the factors and the factor loadings are separately identified. ${ }^{2}$ Scale identification is achieved by normalizing the variance of the factor innovations to some positive constant $c$, that is, we set $\sigma_{\varphi}^{2}=c .^{3}$ Sign identification is achieved by restricting one of the factor loadings on each factor to be positive.

The model given by eqs. (1)-(3) can be cast in state-space form and estimated using the Kalman filter and maximum likelihood techniques. This is not the approach pursued in this paper. The fairly large number of unknown parameters in combination with the large number of unobserved states makes the numerical optimization of the sample log-likelihood function quite tedious. Therefore, we analyze the state-space model from a Bayesian point of view using a Gibbs sampler. The Gibbs sampler is a Markov chain Monte Carlo method that simplifies drawing sequences of observations from the joint and marginal posterior distributions of the unknown parameters and the unobserved states by iteratively drawing states and parameters from their conditional distributions. Intuitively, this amounts to reducing sampling from the more complex joint distribution to a sequence of blocks for subsets of parameters/states which are easier to sample conditional on the other blocks in the sequence. For details of the exact implementation, we refer to Kose et al. (2003) and Otrok and Whiteman (1998).

\subsection{Determining the Country Groups}

Prior to estimating the DFM, we determine the number and the compositions of the country groups. Following Ductor and Leiva-Leon (2016), we choose the 
Ward clustering method for partitioning the country sample, as it is one of the most frequently used standard clustering procedures and tends to form clusters of equal sizes, which enhances economic interpretation of business cycle groups. Ward's clustering method successively merges countries and clusters according to the minimal increase in the error sum of squares within a newly formed cluster that can be calculated using

$$
\mathrm{ESQ}_{j}=\sum_{k=1}^{n_{j}} \sum_{t=1}^{T}\left(x_{k t j}-\bar{x}_{t j}\right)^{2}
$$

with $n_{j}$ being the number of countries in cluster $j, x_{k t j}$ denoting observation in $t$ of country $k$ in cluster $j$, and $\bar{x}_{t j}$ denoting the mean of observations at $t$ in cluster $j$. The recursive algorithm starts with merging the pair of countries $(i$ and $h)$ with the smallest squared Euclidean distance between them:

$$
d=\sum_{t=1}^{T}\left(x_{i t}-x_{h t}\right)^{2}
$$

where $x_{i / h t}$ is the observation in $t$ of countries $i$ and $h$. At each step of the following procedure, the distance between a newly created cluster of countries B $+\mathrm{C}$ and any other country A can be recalculated using

$$
\begin{aligned}
D(\mathrm{~A} ; \mathrm{B}+\mathrm{C})= & \frac{1}{n^{A}+n^{B}+n^{C}} \times\left\{\left(n^{A}+n^{B}\right) \times d(A ; B)+\left(n^{A}+n^{C}\right)\right. \\
& \left.\times d(A ; C)-n^{A} \times d(B ; C)\right\}
\end{aligned}
$$

with $n^{A}, n^{B}, n^{C}$ denoting the number of objects in clusters A, B, and C. Note that these distances correspond to twice the increase of the sum of squares within the formed clusters.

The hierarchical clustering allows to take the country grouping obtained at any level of aggregation. For the interpretation of the final results, however, it might be interesting to know what number of clusters should be optimally assumed. This is especially important when comparing the results of the first with the second period, as within both time periods different numbers of clusters might fit the data just as well. For the determination of an optimal number of clusters, we consider the two widely used cluster stopping rules developed by Calinski and Harabasz (1974) and Duda and Hart (1973), which were found to perform best among many others [for an overview and application test, see Milligan and Cooper (1985)]. We compute the values on a range between three and ten possible clusters, as two clusters appear too few and more than the square root of $n$ too many for reasonable economic interpretation. The higher the values of both indices the more distinct is the clustering. The results can be seen in the Appendix Table A2.

\subsection{Data}

For reasons of comparability, we create the same global dataset of 106 countries and three macroeconomic aggregates (real GDP, real consumption, and real investment) that has been used in the literature. Moreover, the lack of data 
availability for such a large selection of countries makes it difficult to extend the number of variables considerably, for example, to include financial indicators. This would require reducing the country sample and merging two different strands of the literature, which is beyond the scope of this paper and merits further research. All data have been obtained from Penn World Table 9.0 covering an extended time period of annual observations from 1960 to 2014. We use the aggregates with constant prices expressed in local currencies and compute the growth rates for each time series. For the cluster analysis, which is based on all three variables, the data have been z-standardized in order to achieve an equal weighting. The DFM is then estimated with demeaned growth series in line with Kose et al. (2012). To compare the results due to different country group specifications, the sample can be partitioned into the seven regional groups (NA: Europe; Oceania; Asia; Latin America and the Caribbean (LAC); Middle East and North Africa (MENA); and Sub-Saharan Africa (SSA)) used by Hirata et al. (2013), as well as into the three development-based groups (23 IEs, 24 EMs, and 59 DEs) set by Kose et al. (2012). A detailed list of the countries of each group can be found in the Appendix (Table A1). Following these authors, we also divide the sample into the pre-globalization period (1960-1984) and the globalization period (1985-2014) in order to reassess the previously detected "decoupling" and "regionalization" trends based on different country groupings.

\section{RESULTS}

\subsection{The Country Group Pattern of International Business Cycles}

Figure 1 shows the hierarchical grouping structure of the business cycle data for the full sample period in the form of a dendrogram. Starting with 106 individual country clusters at the bottom, countries and clusters are successively merged using Ward's clustering method until only one cluster is left. The most obvious division arising is that between all the IEs on the left side, and the EMs and DEs together on the right side of the dendrogram. When the sample is further partitioned into three clusters, the latter two country groups can, however, not be clearly separated as supposed by Kose et al. (2012). Whereas, for instance, many of the Central American DEs are grouped into the second cluster also containing the majority of the 24 EMs of the sample, some mainly South Asian EMs (e.g., China, India, Egypt, Pakistan, Jordan) rather belong to the third cluster of otherwise mostly African DEs.

Moving further to the bottom of the dendrogram by separating four, five, six, and seven clusters reveals some regional similarities in the data, most evidently in Central Europe, Southeast Asia, Latin America, and parts of Africa. When seven clusters are supposed, the country groups can roughly be labeled as the following: 1. Cluster: "Central Europe"; 2. Cluster: "Anglo-Saxon"; 3. Cluster: "Latin America"; 4. Cluster: "Southeast Asia"; 5. Cluster: "South Asia and Africa"; 6. Cluster: "Middle East and Africa"; and 7. Cluster: "Africa." The group compositions, however, do not correspond to the seven regions that have been set by 


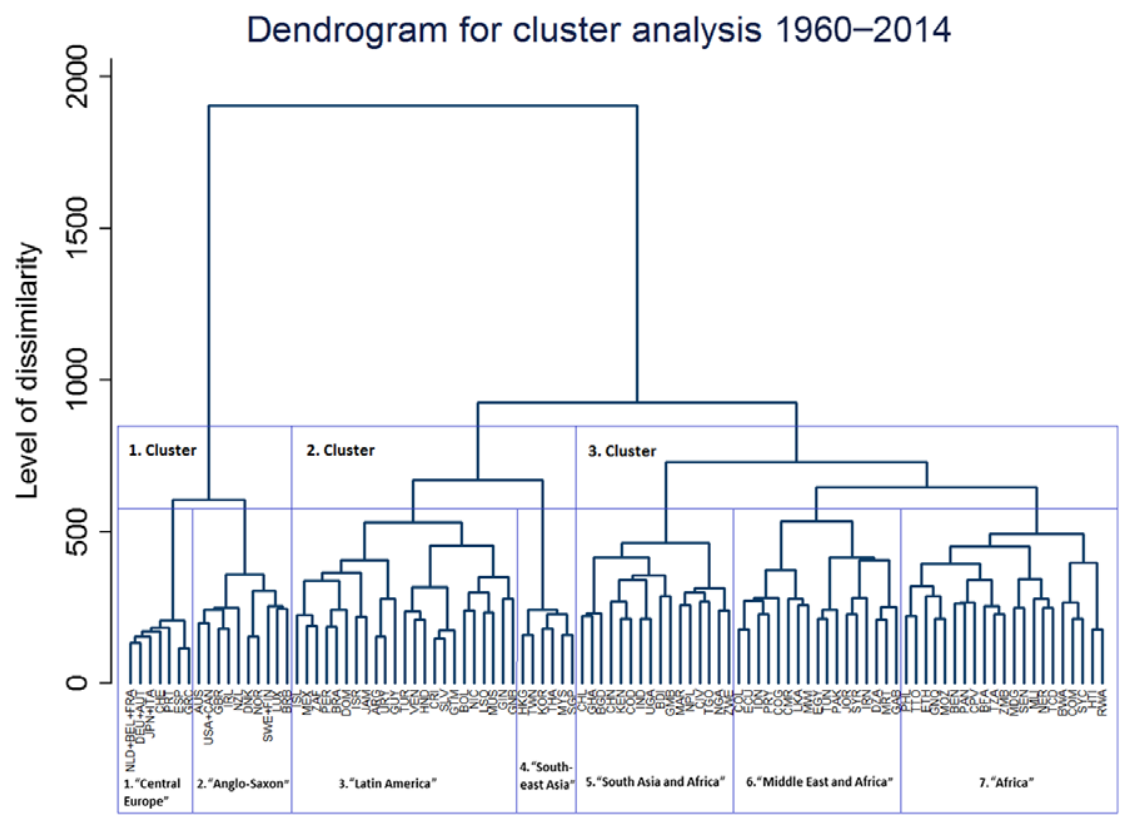

Note $(s)$ : For reasons of clarity, the country ISO codes have been used and branches have been limited to 100 so that the countries being most similar are summarized (e.g., NLD + BEL + FRA). A list of countries along with the ISO codes can be found in the Appendix. The boxes indicate the cluster compositions at the three- and seven-cluster levels.

FIGURE 1. Hierarchical grouping structure (1960-2014).

Hirata et al. (2013). For instance, countries of NA (USA and Canada) and Oceania (New Zealand and Australia) rather form a common cluster together with Anglo-Saxon and Northern European countries (Ireland, UK, Denmark, Sweden, Norway and Finland), providing evidence of inter-regional cyclical commonalities that were similarly found between these groups by the clustering approaches of Ductor and Leiva-Leon (2016) and Francis et al. (2017), but based on different and smaller databases. The only clusters found to comprise almost exclusively countries of the same region are the first cluster of Central European countries and the fourth cluster of Southeast Asian economies. Interestingly, Japan in fact is not grouped with its regional neighbors but with the European countries, indicating stronger commonalities between these IEs.

In sum, the country group pattern obtained by the clustering approach reveals cyclical similarities different from what has been previously supposed in the DFM conducted by Kose et al. (2012) and Hirata et al. (2013). The grouping structure of the data is rather a mix of both, carrying implications for the DFM conducted in the next section. Regarding the optimal number of clusters, we find no clear evidence as to how many groups should be used (see Table A2 in the Appendix). While the first index does not indicate any superior cluster solution as its values 
(a)

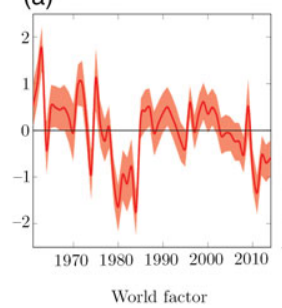

(e)

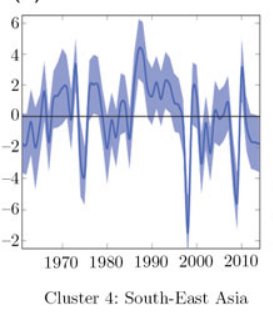

(b)

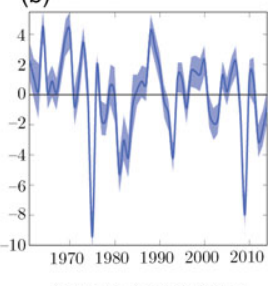

Cluster 1: Central Europe

(f)

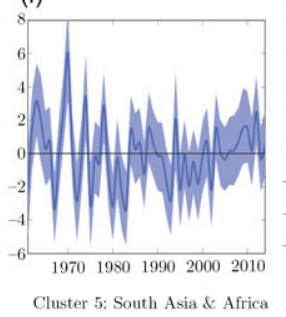

(c)

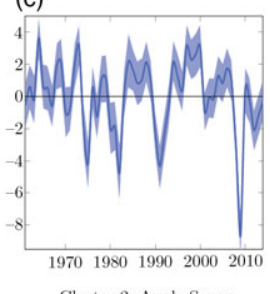

(g)

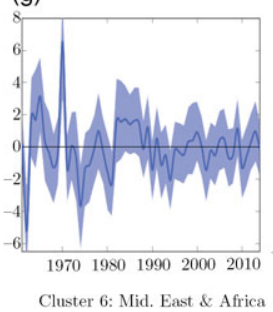

(d)

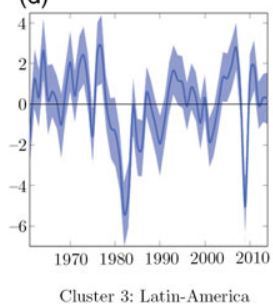

(h)

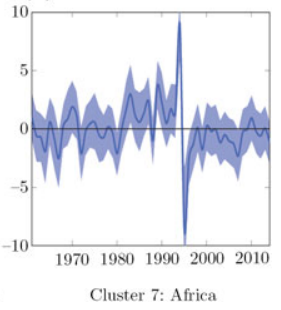

Note(s): We show the posterior means of the global (upper left panel) and the group-specific factors along with the 5\% and 95\% quantile bands of the DFM when seven clusters have been imposed.

FIGURE 2. Global and group-specific factors (1960-2014). (a) World factor. (b) Cluster 1: Central Europe. (c) Cluster 2: Anglo-Saxon. (d) Cluster 3: Latin America. (e) Cluster 4: South-East Africa. (f) Cluster 5: South Asia and Africa. (g) Cluster 6: Mid East and Africa. (h) Cluster 7: Africa.

decrease continually with the number of clusters, the Duda-Hart Index prefers the three-cluster solution over the others. Thus, one first result is that the assumed number of clusters used by Kose et al. (2012) seems more accurate than that of Hirata et al. (2013), but in either case the group compositions do not fit the data. In the following section, we use both the three- and seven-cluster solutions, allowing us to directly compare our results regarding the importance of group factors based on an equivalent number of clusters.

\subsection{The Importance of the Group Specification in DFM}

Figure 2 depicts the posterior mean of the global and group-specific factors together with the respective $5 \%$ and $95 \%$ quantile bands of the estimates of the DFM when seven groups have been set according to the dendrogram. We show this specification, as the group-specific factors can be interpreted more easily from clusters containing smaller intuitive country groups with less variation.

It can be seen in the upper left panel that the global factor captures some major economic events that have been experienced all around the world. For example, the drastic downturns following the oil crises of 1973/1974 and 1979 are as clearly visible as the recession in the 1990s and the reversing dynamic in the beginning of the 2000s. By contrast, the immediate impact of the more recent 
financial crises is rather captured by the first four group-specific factors comprising primarily European, Anglo-Saxon, Latin American, and Southeast Asian countries, respectively. While the recessions of 2008/2009 were most pronounced in Europe (Cluster 1) and the Anglo-Saxon countries (Cluster 2), many of these countries also experienced another prolonged downswing visible after the first recovery phase, indicating a so-called double dip recession. The other groupspecific factors as well as the global factor evolved somewhat differently during that time. Overall, this may be interpreted consistent with the presumption of recently declining importance of the global factor due to more group-specific economic developments. Specific regional events such as the Asian crisis in the late 1990s, for example, are captured by the group factor of Cluster 4.

Table 1 shows the variance decompositions from the DFM conducted with different group specifications. Columns 1 and 3 for each variable present the results of the DFM using the country classifications of Kose et al. (2012) and Hirata et al. (2013), respectively. In columns 2 and 4, we report the variances explained that are calculated from the DFM based on the corresponding clustering of the previous section.

When three groups are assumed based on the levels of development, for all 106 countries, the global factor, on average, accounts for a remarkable fraction of output- $(9.1 \%)$, consumption- $(9.6 \%)$, and-to a lesser degree-investment $(4.1 \%)$ growth variability (column 1 ). For the case of seven regions (column $3)$, these numbers are even higher $(10.2 \%, 10.3 \%$, and $4.7 \%)$, indicating the importance of the grouping structure that has been set beforehand. These figures, however, hide a substantial variation across different subsets of countries, with a much higher variance explained among the IEs. For instance, the global factor in columns 1 and 3, on average, accounts for $25 \%$ and $29.1 \%$ of the output variability in the IEs, while it only explains $5.7 \%$ and $4.3 \%$ and $6.4 \%$ and $4.4 \%$ of the volatility of GDP growth rates among the EMs and DEs, respectively. By contrast, for all three variables and all subsets of countries, the global factor's importance decreases dramatically when the groups are specified according to the cyclic similarities of the countries (columns 2 and 4), implying that, if there is a "global business cycle," its relevance in fact is very much limited to the industrialized world (and most significant in consumption growth). While for the whole sample, the contribution of the global factor shrinks to, on average, about $5.2 \%$ or $4.4 \%$ of the output variability in the second and fourth models, within the latter group of countries, it still accounts for $11.5 \%$ or $8.5 \%$. This drop by just about a half in world average of the global factor's relative importance is similarly found for consumption and investment growth rates. However, the deviations between the models are even more pronounced for the G-7 countries with the average output variance explained varying between $33.4 \%$ in the third and $7.8 \%$ in the fourth model. Similarly, the global factor's importance for, say, output volatility differs substantially for important countries like the USA and Canada, depending on whether they are grouped together with all other IEs of the sample (21\%), with 
TABLE 1. Variance decompositions using different country groupings for the full sample period (1960-2014)

\begin{tabular}{|c|c|c|c|c|c|c|c|c|c|c|c|c|c|}
\hline \multirow[b]{2}{*}{ Group } & \multirow[b]{2}{*}{ Factor } & \multicolumn{4}{|c|}{ Output } & \multicolumn{4}{|c|}{ Consumption } & \multicolumn{4}{|c|}{ Investment } \\
\hline & & $\begin{array}{c}\text { Three } \\
\text { development } \\
\text { stages }\end{array}$ & $\begin{array}{l}\text { Three } \\
\text { clusters }\end{array}$ & $\begin{array}{l}\text { Seven } \\
\text { regions }\end{array}$ & $\begin{array}{l}\text { Seven } \\
\text { clusters }\end{array}$ & $\begin{array}{c}\text { Three } \\
\text { development } \\
\text { stages }\end{array}$ & $\begin{array}{l}\text { Three } \\
\text { clusters }\end{array}$ & $\begin{array}{l}\text { Seven } \\
\text { regions }\end{array}$ & $\begin{array}{l}\text { Seven } \\
\text { clusters }\end{array}$ & $\begin{array}{c}\text { Three } \\
\text { development } \\
\text { stages }\end{array}$ & $\begin{array}{l}\text { Three } \\
\text { clusters }\end{array}$ & $\begin{array}{l}\text { Seven } \\
\text { regions }\end{array}$ & $\begin{array}{l}\text { Seven } \\
\text { clusters }\end{array}$ \\
\hline \multirow[t]{5}{*}{ World } & Global & 9.13 & 5.21 & 10.21 & 4.39 & 9.56 & 6.62 & 10.28 & 5.83 & 4.07 & 2.71 & 4.70 & 2.54 \\
\hline & Group & 11.05 & 14.49 & 14.76 & 18.84 & 6.41 & 8.96 & 7.66 & 13.62 & 9.43 & 11.05 & 9.85 & 12.50 \\
\hline & International & 20.18 & 19.71 & 24.97 & 23.23 & 15.97 & 15.58 & 17.94 & 19.46 & 13.50 & 13.76 & 14.55 & 15.04 \\
\hline & Country & 48.00 & 48.62 & 44.69 & 45.17 & 40.56 & 40.26 & 38.27 & 38.43 & 29.09 & 29.23 & 28.62 & 29.17 \\
\hline & Idiosyncratic & 31.82 & 31.67 & 30.34 & 31.60 & 43.46 & 44.16 & 43.79 & 42.11 & 57.41 & 57.01 & 56.83 & 55.79 \\
\hline \multirow[t]{5}{*}{ IE } & Global & 25.03 & 11.47 & 29.13 & 8.46 & 29.03 & 18.65 & 31.62 & 15.88 & 9.96 & 4.62 & 12.08 & 4.02 \\
\hline & Group & 22.48 & 36.52 & 22.40 & 43.78 & 7.42 & 18.29 & 8.55 & 25.01 & 25.01 & 30.50 & 26.93 & 32.94 \\
\hline & International & 47.51 & 47.99 & 51.53 & 52.24 & 36.45 & 36.95 & 40.17 & 40.89 & 34.98 & 35.12 & 39.01 & 36.96 \\
\hline & Country & 37.76 & 37.24 & 33.70 & 33.17 & 31.73 & 31.14 & 28.20 & 27.62 & 41.12 & 41.10 & 37.64 & 39.23 \\
\hline & Idiosyncratic & 14.73 & 14.77 & 14.76 & 14.60 & 31.83 & 31.91 & 31.63 & 31.48 & 23.90 & 23.78 & 23.35 & 23.81 \\
\hline \multirow[t]{5}{*}{ EM } & Global & 5.74 & 3.35 & 6.40 & 3.06 & 5.54 & 3.95 & 5.91 & 3.62 & 2.38 & 2.49 & 2.49 & 2.57 \\
\hline & Group & 11.97 & 11.75 & 16.57 & 15.53 & 8.77 & 7.62 & 10.54 & 10.95 & 9.58 & 8.59 & 9.61 & 9.94 \\
\hline & International & 17.71 & 15.10 & 22.97 & 18.59 & 14.31 & 11.57 & 16.45 & 14.57 & 11.96 & 11.08 & 12.10 & 12.51 \\
\hline & Country & 61.29 & 63.85 & 57.50 & 60.93 & 47.15 & 49.64 & 45.31 & 48.21 & 39.23 & 39.58 & 39.02 & 39.94 \\
\hline & Idiosyncratic & 21.00 & 21.04 & 19.52 & 20.48 & 38.54 & 38.79 & 38.24 & 37.22 & 48.81 & 49.34 & 48.88 & 47.55 \\
\hline \multirow[t]{5}{*}{$\mathrm{DE}$} & Global & 4.31 & 3.53 & 4.38 & 3.34 & 3.61 & 3.02 & 3.74 & 2.82 & 2.46 & 2.06 & 2.72 & 1.95 \\
\hline & Group & 6.22 & 7.02 & 11.04 & 10.47 & 5.06 & 5.87 & 6.13 & 10.28 & 3.29 & 4.46 & 3.29 & 5.58 \\
\hline & International & 10.53 & 10.55 & 15.43 & 13.81 & 8.67 & 8.89 & 9.88 & 13.09 & 5.75 & 6.52 & 6.01 & 7.52 \\
\hline & Country & 46.59 & 46.86 & 43.77 & 43.44 & 41.33 & 39.99 & 39.33 & 38.66 & 20.27 & 20.40 & 20.88 & 20.86 \\
\hline & Idiosyncratic & 42.87 & 42.59 & 40.81 & 42.75 & 50.00 & 51.12 & 50.79 & 48.25 & 73.98 & 73.08 & 73.11 & 71.61 \\
\hline
\end{tabular}


TABLE 1. Continued

\begin{tabular}{|c|c|c|c|c|c|c|c|c|c|c|c|c|c|}
\hline \multirow[b]{2}{*}{ Group } & \multirow[b]{2}{*}{ Factor } & \multicolumn{4}{|c|}{ Output } & \multicolumn{4}{|c|}{ Consumption } & \multicolumn{4}{|c|}{ Investment } \\
\hline & & $\begin{array}{c}\text { Three } \\
\text { development } \\
\text { stages }\end{array}$ & $\begin{array}{l}\text { Three } \\
\text { clusters }\end{array}$ & $\begin{array}{l}\text { Seven } \\
\text { regions }\end{array}$ & $\begin{array}{l}\text { Seven } \\
\text { clusters }\end{array}$ & $\begin{array}{c}\text { Three } \\
\text { development } \\
\text { stages }\end{array}$ & $\begin{array}{l}\text { Three } \\
\text { clusters }\end{array}$ & $\begin{array}{l}\text { Seven } \\
\text { regions }\end{array}$ & $\begin{array}{l}\text { Seven } \\
\text { clusters }\end{array}$ & $\begin{array}{c}\text { Three } \\
\text { development } \\
\text { stages }\end{array}$ & $\begin{array}{l}\text { Three } \\
\text { clusters }\end{array}$ & $\begin{array}{l}\text { Seven } \\
\text { regions }\end{array}$ & $\begin{array}{l}\text { Seven } \\
\text { clusters }\end{array}$ \\
\hline \multirow[t]{5}{*}{ G-7 } & Global & 28.23 & 11.68 & 33.36 & 7.82 & 36.89 & 23.40 & 39.77 & 19.20 & 11.40 & 3.42 & 14.49 & 2.54 \\
\hline & Group & 23.52 & 39.91 & 28.62 & 55.84 & 7.83 & 21.06 & 12.60 & 36.34 & 28.73 & 36.49 & 38.77 & 46.62 \\
\hline & International & 51.74 & 51.59 & 61.98 & 63.66 & 44.72 & 44.46 & 52.37 & 55.55 & 40.13 & 39.91 & 53.25 & 49.17 \\
\hline & Country & 38.22 & 38.30 & 28.14 & 26.61 & 31.24 & 31.38 & 22.72 & 20.85 & 46.72 & 46.96 & 33.83 & 37.73 \\
\hline & Idiosyncratic & 10.04 & 10.11 & 9.88 & 9.73 & 24.04 & 24.16 & 24.91 & 23.60 & 13.14 & 13.13 & 12.92 & 13.10 \\
\hline \multirow[t]{5}{*}{ USA-CAN } & Global & 20.97 & 9.23 & 23.82 & 5.08 & 27.28 & 16.81 & 28.92 & 11.59 & 3.92 & 0.94 & 4.74 & 0.87 \\
\hline & Group & 14.99 & 26.56 & 49.02 & 60.43 & 6.88 & 17.68 & 31.09 & 45.69 & 13.21 & 15.99 & 61.77 & 44.47 \\
\hline & International & 35.96 & 35.80 & 72.85 & 65.51 & 34.16 & 34.49 & 60.00 & 57.29 & 17.13 & 16.93 & 66.51 & 45.34 \\
\hline & Country & 53.02 & 53.18 & 16.75 & 24.46 & 42.74 & 42.74 & 16.37 & 20.48 & 72.01 & 72.87 & 23.31 & 44.18 \\
\hline & Idiosyncratic & 11.02 & 11.03 & 10.40 & 10.03 & 23.10 & 22.77 & 23.62 & 22.23 & 10.86 & 10.21 & 10.18 & 10.48 \\
\hline \multirow[t]{5}{*}{ EU-12 } & Global & 32.77 & 15.57 & 38.09 & 11.96 & 36.60 & 24.09 & 39.67 & 20.88 & 14.53 & 5.93 & 17.70 & 4.84 \\
\hline & Group & 25.98 & 43.66 & 20.28 & 48.29 & 7.17 & 20.04 & 4.02 & 27.17 & 29.49 & 38.07 & 26.29 & 38.72 \\
\hline & International & 58.75 & 59.24 & 58.37 & 60.26 & 43.77 & 44.13 & 43.69 & 48.06 & 44.02 & 44.00 & 43.99 & 43.56 \\
\hline & Country & 28.43 & 27.89 & 28.75 & 26.74 & 24.48 & 23.81 & 24.48 & 21.22 & 33.60 & 33.51 & 33.78 & 34.06 \\
\hline & Idiosyncratic & 12.82 & 12.87 & 12.88 & 13.01 & 31.75 & 32.06 & 31.83 & 30.72 & 22.37 & 22.49 & 22.23 & 22.38 \\
\hline
\end{tabular}

Note(s): We estimate the DFM using group-specific factors with different country classifications (three development stages, three clusters, seven regions, and seven clusters) and display the mean variances explained of output, consumption, and investment growth rates by all the factors and the sum of international factors (Global + Group-specific). In line with the literature, we report the cross-sectional averages of all countries (world) as well as several subsets (IE, EM, DE, G-7, USA-CAN, and EU-12). 
Mexico on a regional basis $(23.8 \%)$, or with the cluster members of the equivalent cluster numbers $(9.2 \%$ or $5.1 \%)$.

Conversely, and in line with Francis et al. (2017), we find that, overall, the group-specific factors gain importance when the countries are classified according to their cyclical similarity. For the results obtained with three development-related groups, the group-specific factors, on average, explain $11.1 \%, 6.4 \%$, and $9.4 \%$ of all the countries' macroeconomic fluctuations, respectively (column 1). Assuming seven regions instead, the regional component captures $14.8 \%, 7.7 \%$, and $9.9 \%$ of the variability of output, consumption, and investment growth rates, respectively (column 3). Finally, when the underlying classification is based on the corresponding clusters drawn from the dendrogram (columns 2 and 4), the groupspecific factors account for a larger fraction of the variability of output $(14.5 \%$ or $18.8 \%)$, consumption $(9.0 \%$ or $13.6 \%)$, and investment $(11 \%$ or $12.5 \%)$ growth rates. Again, these average deviations may seem small but are based on a sample of 106 countries and differ substantially across many subsets. For instance, the fraction of output growth attributable to the group-specific factors of the USA and Canada varies between $15 \%$ of the IE factor, $49 \%$ of the regional factor, and between $26.6 \%$ and $60.4 \%$ of the corresponding cluster-specific factors. Similarly, the "European business cycle," which loads over all 18 sample countries of the European continent, explains, on average, $20.3 \%$ of the output variation of the EU-12 countries, compared with $43.7 \%$ or $48.3 \%$ of the average EU-12 country's output growth captured by the cluster-specific factors.

Besides the deviations in the relative importance of global and group-specific factors, we find that the overall contribution of international factors relative to the domestic and idiosyncratic components does not change much at world average.

\subsection{Changing Country Group Pattern and Implications for the "decoupling" Trend}

After having shown the importance of properly specifying the group-specific factors for the full sample, we now turn to the country group patterns that have been established in the pre- and the globalization eras. Moreover, by assuming the optimal number of clusters in each period, we gain a better understanding of the extent of "decoupling" of IEs and EMs or the "regionalization" that has been detected by the literature.

Figure 3 illustrates the dendrograms obtained by the cluster analyses of each period. For the pre-globalization period, the grouping of countries does not much reflect the previous assumptions of seven regional or three development-driven group-specific business cycles. Specific regional commonalities are most visible in the first European cluster at the two-cluster level and otherwise limited to NA and Central America and some neighboring countries at lower aggregation levels. There is also a clear division among the IEs, as, for instance, the USA, Canada, and the UK are found to be separated from the European IEs and Japan. For most groups, there seems to exist no obvious economic explanation as to why member 
(a)

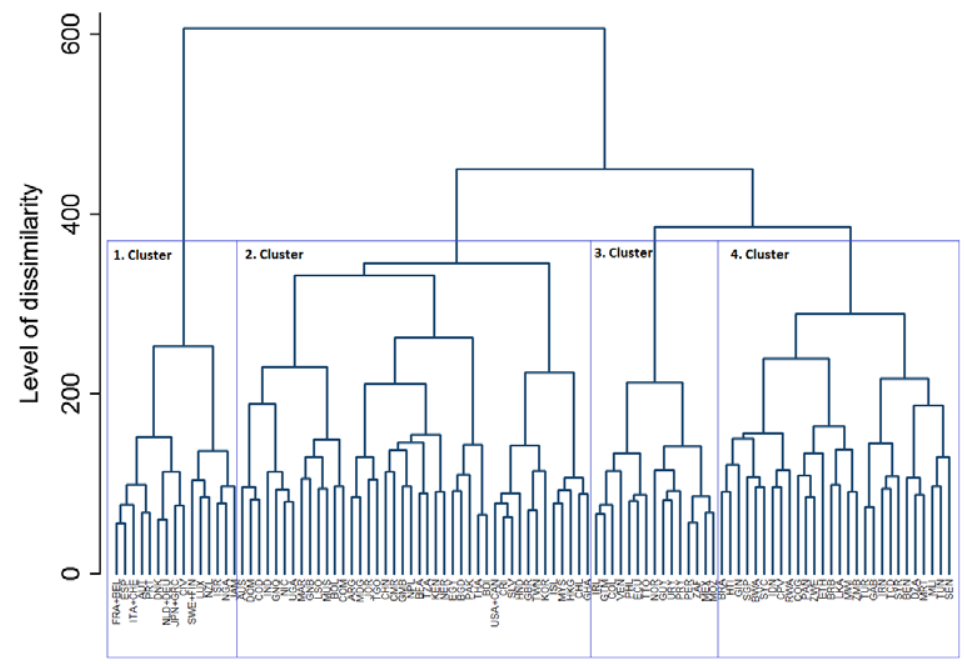

(b) Dendrogram for cluster analysis 1985-2014

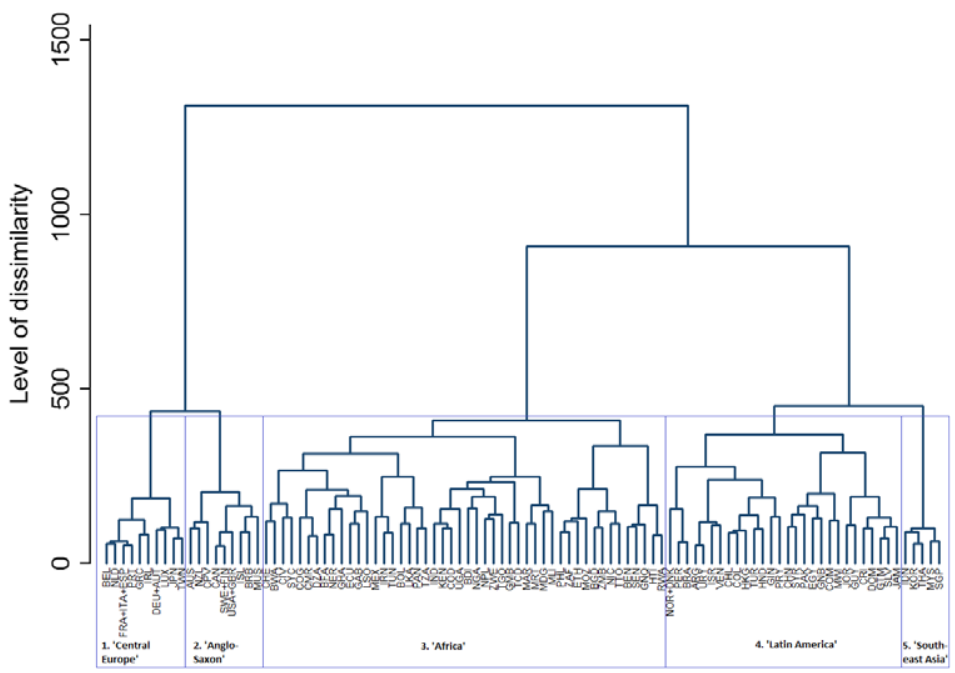

Note(s): (a) For reasons of clarity, the country ISO codes have been used and branches have been limited to 100 so that the countries found most similar are summarized (e.g., FRA + BEL). A list of countries along with the ISO codes can be found in the Appendix. The boxes refer to the optimal number of clusters indicated in Table A2 of the Appendix. (b) For reasons of clarity, the country ISO codes have been used and branches have been limited to 100 so that the countries found most similar are summarized (e.g., DEU + AUT). A list of countries along with the ISO codes can be found in the Appendix.

FIGURE 3. (a) Hierarchical grouping structure (1960-1984). (b) Hierarchical grouping structure (1985-2014). 
countries share cyclic commonalities, suggesting that multilateral trade pattern was not yet developed for large parts of the sample. It seems more that the clustering algorithm inevitably merges countries and groups (with some unintuitive constellations $^{4}$ ) that do not all necessarily share strong common explanatory factors. That said, it may be no surprise why even the group-specific factors imposed ex ante by Kose et al. (2003, 2012) and Hirata et al. (2013) explain only a negligible fraction of macroeconomic growth rates in the pre-globalization period.

In the second period, however, the country group pattern corresponds more closely to both regional proximity and the level of development. While the division between the bulk of the IEs, on the one hand, and the EMs and DEs, on the other hand, is most visible at the two-cluster level, at least most of the (African) DEs are clustered together into a further subgroup, separated clearly from 18 out of 24 EMs on the right side of the dendrogram. Regional linkages are found to exist with increasing accuracy downwards from the five-cluster level, where the clusters can roughly be labeled as the following: 1. Cluster: "Central Europe"; 2. Cluster: "Anglo-Saxon"; 3. Cluster: "Africa"; 4. Cluster: "Latin America"; and 5. Cluster: "Southeast Asia." However, the Anglo-Saxon cluster confirms some inter-regional similarities in the business cycles. This is also true for Japan and Taiwan, which are grouped together with the Central European countries.

What does this change in the group pattern of business cycles suggest about the previously detected growing importance of intragroup factors and declining relevance of the global factor over time? While it certainly indicates some development-related fragmentation and regionalization of the world's economic system after the mid-1980s, the "decoupling" of country groups is likely to have occurred in a slightly different constellation than between the IEs, Ems, or some specific regional clusters. While these country groups, indeed, have developed increasing ties in the second period, this does not necessarily mean that intragroup factors exhibited lower importance for such countries before. In fact, the groups were just different. Taking the data-based group structures in both periods instead will give us some indication of to what extent the group-specific factors' relative importance has actually changed. In combination with the optimal number of clusters shown in Table A2 in the Appendix, we can run the DFM for each period separately in order to verify the respective changes in the variance decompositions.

Table 2 depicts the variance decompositions for both subperiods with varying country group specifications. In line with the "decoupling" thesis, we find that the global factor's importance decreases for all countries and variables from the first to the second period (except for some countries' investment activity) regardless of what groups have been imposed. Whereas it explained, on average, up to $14.7 \%$ of the volatility of output, consumption, and investment growth in the preglobalization era, respectively, it captures at maximum $9 \%$ of the macroeconomic fluctuations in the second period within all model specifications. When the group-specific factors are modeled according to the clustering, the importance 
TABLE 2. Variance decompositions using different country groupings for subperiods 1960-1984 and 1985-2014

\begin{tabular}{|c|c|c|c|c|c|c|c|c|c|c|c|c|c|c|c|c|c|c|c|}
\hline \multirow[b]{4}{*}{ Group } & \multirow{4}{*}{$\begin{array}{l}\text { Country } \\
\text { grouping }\end{array}$} & \multicolumn{6}{|c|}{ Output } & \multicolumn{6}{|c|}{ Consumption } & \multicolumn{6}{|c|}{ Investment } \\
\hline & & \multicolumn{2}{|c|}{$\begin{array}{c}\text { Three } \\
\text { development } \\
\text { stages }\end{array}$} & \multicolumn{2}{|c|}{$\begin{array}{l}\text { Seven } \\
\text { regions }\end{array}$} & \multicolumn{2}{|c|}{$\begin{array}{l}\text { Four or } \\
\text { Five } \\
\text { clusters }\end{array}$} & \multicolumn{2}{|c|}{$\begin{array}{c}\text { Three } \\
\text { development } \\
\text { stages }\end{array}$} & \multicolumn{2}{|c|}{$\begin{array}{l}\text { Seven } \\
\text { regions }\end{array}$} & \multicolumn{2}{|c|}{$\begin{array}{l}\text { Four or } \\
\text { Five } \\
\text { clusters }\end{array}$} & \multicolumn{2}{|c|}{$\begin{array}{c}\text { Three } \\
\text { development } \\
\text { stages }\end{array}$} & \multicolumn{2}{|c|}{ regions } & \multicolumn{2}{|c|}{$\begin{array}{l}\text { Four or } \\
\text { Five } \\
\text { clusters }\end{array}$} \\
\hline & & 1. & 2. & 1. & 2. & 1. & 2. & 1. & 2. & 1. & 2. & 1. & 2. & 1. & 2. & 1. & 2. & 1. & 2. \\
\hline & & Period & Period & Period & Period & Period & Period & Period & Period & Period & Period & Period & Period & Period & Period & Period & Period & Period & Period \\
\hline \multirow[t]{5}{*}{ World } & Global & 69 & 8.89 & 14.49 & 8.98 & 12.83 & 7.96 & 13.88 & 6.96 & 13.69 & 7.04 & 13.04 & 5.8 & 7.50 & 5.67 & 7.53 & 6.05 & 6.58 & 6.04 \\
\hline & Group & 7.41 & 20.74 & 9.89 & 22.13 & 12.94 & 24.53 & 6.77 & 14.90 & 8.63 & 16.60 & 8.58 & 19.27 & 8.38 & 14.29 & 8.26 & 15.76 & 9.80 & 16.18 \\
\hline & International & 22.10 & 29.63 & 24.38 & 31.11 & 25.77 & 32.49 & 20.65 & 21.86 & 22.31 & 23.64 & 21.62 & 25.14 & 15.88 & 19.96 & 15.79 & 21.81 & 16.38 & 22.21 \\
\hline & Country & 49.85 & 39.17 & 47.65 & 37.53 & 46.59 & 36.76 & 41.83 & 34.94 & 41.04 & 33.66 & 40.40 & 31.99 & 31.55 & 34.69 & 31.29 & 32.71 & 30.65 & 33.52 \\
\hline & Idiosyncratic & 28.05 & 31.20 & 27.97 & 31.36 & 27.64 & 30.75 & 37.52 & 43.20 & 36.65 & 42.71 & 37.98 & 42.87 & 52.57 & 45.35 & 52.91 & 45.47 & 52.96 & 44.27 \\
\hline \multirow[t]{5}{*}{ IE } & obal & 31.21 & 6.68 & 32.20 & 9.64 & 26.61 & 6.30 & 33.31 & 10.21 & 33.87 & 11.48 & 31.62 & 6.16 & 13.47 & 9.87 & 14.13 & 11.61 & 10.83 & 9.65 \\
\hline & Group & 11.82 & 50.12 & 12.46 & 50.12 & 20.71 & 54.08 & 3.40 & 35.21 & 3.90 & 34.80 & 9.20 & 42.25 & 16.79 & 34.97 & 17.98 & 37.25 & 21.64 & 37.96 \\
\hline & International & 43.03 & 56.80 & 44.65 & 59.76 & 47.31 & 60.38 & 36.71 & 45.42 & 37.77 & 46.28 & 40.82 & 48.41 & 30.26 & 44.84 & 32.11 & 48.86 & 32.47 & 47.60 \\
\hline & Country & 41.30 & 25.18 & 39.69 & 23.07 & 37.04 & 21.78 & 32.16 & 21.48 & 31.99 & 20.17 & 28.09 & 18.86 & 46.62 & 32.95 & 45.31 & 29.84 & 45.00 & 31.59 \\
\hline & Idiosyncratic & 15.67 & 18.02 & 15.65 & 17.17 & 15.65 & 17.84 & 31.13 & 33.10 & 30.24 & 33.56 & 31.09 & 32.73 & 23.12 & 22.21 & 22.58 & 21.30 & 22.54 & 20.81 \\
\hline \multirow[t]{5}{*}{ EM } & Global & 18.11 & 8.49 & 12.94 & 8.22 & 11.77 & 7.41 & 10.99 & 8.01 & 10.98 & $1.2 \mathrm{~J}$ & 9.95 & 7.68 & 4.08 & 5.20 & 4.62 & 5.06 & 4.34 & 6.08 \\
\hline & Group & 6.08 & 24.04 & 9.78 & 24.01 & 11.63 & 25.84 & 9.55 & 15.69 & 6.16 & 18.56 & 9.54 & 20.36 & 7.65 & 18.29 & 7.27 & 18.88 & 7.27 & 18.64 \\
\hline & International & 19.25 & 32.53 & 22.72 & 32.23 & 23.40 & 33.25 & 20.54 & 23.71 & 17.14 & 25.82 & 19.50 & 28.04 & 12.33 & 23.49 & 11.90 & 23.94 & 11.61 & 24.72 \\
\hline & Country & 54.92 & 49.83 & 51.27 & 50.25 & 50.30 & 49.09 & 43.51 & 46.62 & 45.30 & 45.56 & 42.24 & 43.02 & 39.72 & 44.23 & 39.14 & 43.79 & 39.09 & 43.88 \\
\hline & Idiosyncratic & 25.84 & 17.64 & 26.01 & 17.52 & 26.30 & 17.66 & 35.96 & 29.67 & 37.56 & 28.62 & 38.26 & 28.93 & 47.95 & 32.29 & 48.96 & 32.27 & 49.30 & 31.40 \\
\hline
\end{tabular}




\section{TABLE 2. Continued}

\begin{tabular}{|c|c|c|c|c|c|c|c|c|c|c|c|c|c|c|c|c|c|c|c|}
\hline \multirow[t]{3}{*}{ DE } & lobal & 8.86 & 9.92 & 8.22 & 9.03 & 7.90 & 8.83 & 7.48 & 5.26 & 6.92 & 5.22 & 7.06 & 6.01 & 6.31 & 4.22 & 6.14 & 4.29 & 5.83 & 6.17 \\
\hline & roup & 6.24 & 7.94 & 8.94 & 0.46 & 10.45 & 18.41 & 6.96 & 6.66 & 11.47 & 8.70 & 7.94 & 14.10 & 5.41 & 4.61 & 4.88 & 6.11 & 6.22 & 12.11 \\
\hline & Country & .12 & 40.29 & 49.28 & 37.99 & 48.80 & 39.57 & 4.92 & 5.44 & 42.84 & 4.08 & 4.45 & 34.65 & 22.36 & 31.49 & 22.64 & 9.33 & 21.63 & 34.46 \\
\hline \multirow[t]{3}{*}{$\mathrm{G}-7$} & & 05 & 1 & .73 & 7 & 2.76 & 36 & .22 & .30 & 2.06 & .07 & .20 & 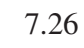 & .98 & & .14 & & 32 & 11.45 \\
\hline & 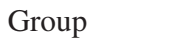 & 9.34 & 55.95 & 12.31 & 58.91 & 22.17 & 66.80 & 2.42 & 2.54 & 3.80 & 3.71 & 13.13 & 53.89 & 16.89 & 40.38 & 21.39 & .86 & 3.97 & 47.77 \\
\hline & & 69 & 12.20 & 9.60 & 7 & 9.97 & 10.95 & 8 & 2 & 7 & 2 & 9 & 23.65 & 4 & 3 & 13 & & 6 & . \\
\hline \multirow{5}{*}{$\begin{array}{l}\text { USA- } \\
\text { CAN }\end{array}$} & & 92 & .48 & 87 & 42 & .31 & 2 & .19 & 34 & 32.89 & .01 & & & 5.10 & & 73 & & 3.76 & 16.6 \\
\hline & 010 & .68 & 47.97 & 17.46 & 63.53 & 25.71 & 71.51 & 1.05 & 43.01 & 8.28 & 46.67 & 22.86 & 66 & 4.01 & 23.86 & 61 & 50.72 & 21.23 & 44.76 \\
\hline & . & .60 & 58.46 & 46.33 & 78.96 & 49.03 & 77.74 & 33.24 & 54.35 & 41.17 & 62.68 & 51.90 & 71 & 9.11 & 34 & 28 & 73.76 & 24.99 & 61. \\
\hline & & .86 & 27.59 & 44.59 & 7.70 & 41.53 & 10.98 & 43.82 & 20.85 & 37.88 & 11.46 & 26.22 & 8.03 & 82.19 & 42.51 & 63.09 & 11.77 & 66.24 & 24.75 \\
\hline & Idi & 53 & 13.96 & 9.08 & 13.34 & 9.45 & 11.28 & 22.93 & 24.80 & 20.95 & 25.86 & 21.88 & 20.52 & 8.70 & 13.65 & 8.57 & 14.47 & 8.78 & 13.87 \\
\hline \multirow{2}{*}{$\mathrm{U}-12$} & Coun & 31.74 & 19.52 & 31.80 & 20.25 & 28.84 & 18.23 & 26.18 & 17.23 & 26.62 & 17.62 & 22.72 & 15.04 & 40.52 & 27.97 & 40.14 & 28.82 & 40.90 & 28.29 \\
\hline & Idiosyncratic & 13.81 & 14.93 & 13.93 & 13.63 & 14.20 & 13.08 & 31.40 & 29.44 & 31.50 & 29.51 & 32.18 & 28.90 & 20.81 & 20.16 & 20.78 & 18.73 & 21.47 & 18.34 \\
\hline
\end{tabular}

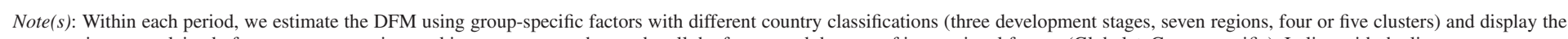
mean variances explained of output, consumption, and investment growth rates by all the factors and the sum of international factors (Global + Group-specific). In line with the literature, we report

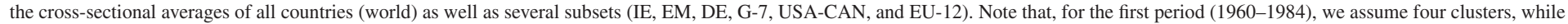
for the second period (1985-2014), five clusters are imposed. 
of the global factor is again the lowest compared with the results from the other groupings in both periods. In the pre-globalization period, however, these deviations in the global factor's importance, on average, are not very high between the models, suggesting again that distinct international country groups around the world did not play the same role as in the second period. The results for the second subsample are robust to limiting the second subsample to the period of financial globalization (1991-2014) instead of trade globalization (1985-2014).

Conversely, the group-specific factors gain importance over time in all specifications with the highest relevance generally found again for the four and five clusters imposed. Different from the first two models, the group-specific factors of the four-cluster model already exhibit almost equal importance as the global factor for output growth in the pre-globalization period. For countries like the USA and Canada, the group factor already played a greater role. Consequently, another substantial deviation exists in the extent to which the importance of intragroup factors increased for some countries depending on the model. Whereas, with the traditional groupings, the figures for IEs went up from $11.8 \%$ and $12.5 \%$ to $50.1 \%$ and $50.1 \%$, respectively, those factors' importance has "only" grown from $20.7 \%$ to $54.1 \%$ based on the DFM using the data-based grouping. Similarly, the average importance of the group-specific factors for the EU-12 countries has risen with factors 4.1 and 4.3 in columns 1 and 2 (from the relatively low levels of $15 \%$ and $13.7 \%$ to $62.1 \%$ and $59.2 \%$ ) compared with factor 2.7 in column 3 (from $23.3 \%$ to $63.3 \%$ ). This confirms the perception from the cluster analysis that the dramatically increasing importance of intragroup factors among IEs, EMs, or within regions highlighted in the literature is partly to be seen as a simple result of these ex ante groupings reflecting reality more closely in the second period.

\section{DISCUSSION}

Another important finding of the above analysis that should be emphasized is that group factors, in whatever constellation, play an increasingly important role for domestic business cycles around the world. It is not necessarily the own region that is the most important factor, but concurrent cycles can also follow global trade patterns, as the Anglo-Saxon cluster suggests. In any case, the increasing nationalism and protectionism that has led to the outbreak of the current trade wars and events such as Brexit is likely to disrupt this system. It remains to be seen whether the associated boost for bilateral trade agreements such as one between the UK and the USA will lead to fragmentation of groups, more idiosyncratic shocks or both. Repeated analyses of this kind can trace changes in the composition of groups and their relevance for local developments. For individual countries facing important decisions such as Brexit, the country-specific variance decompositions could also provide insights into how important corresponding regions, historical groups or the global economy as a whole are.

In this regard, one way of enhancing the present approach would be to model several of these group factors simultaneously. It is certainly also worth 
incorporating more (especially financial) variables - whenever data permits - to investigate global business cycle clusters more comprehensively. However, while the intention here was to compare results with the influential literature on real business cycles, this is left for future research.

\section{CONCLUSION}

The literature on international business cycles has frequently employed DFM presuming the existence of group-specific factors among countries of the same region or at the same level of development. In the present paper, by contrast, we first reveal the data-inherent country group pattern of international business cycles using a cluster analysis and then estimate a DFM accordingly. By comparing the findings with those obtained with the traditional groupings, we show that the correctly specified group factors exhibit much greater, and the global factor much lower, importance for domestic business cycles. The deviations are particularly strong for countries like the USA and Canada that were previously either grouped with Mexico on a regional basis or with all other IEs of the sample. If we assume seven clusters instead of seven world regions, the cluster analysis rather provides evidence of a specific Anglo-Saxon business cycle cluster comprising also the UK, Ireland, Australia, New Zealand, and some Northern European countries.

Regarding the change over time, we find that the country group pattern has evolved toward greater development-related fragmentation and regionalization in the globalization era, explaining to some extent the alleged "decoupling" of IEs and EMs, that is, the growing relevance of the respective group factors and the decreasing importance of the global factor. The group-specific factors of these countries, however, have played a significant role in the pre-globalization era, too, albeit in another constellation.

\section{NOTES}

1. List of covariates: (i) the degree of economic openness, defined as the ratio of imports and exports to GDP; (ii) investment share of real GDP; (iii) an index of conflict resolution and sophistication of the legal system as captured by the manner in which lower courts facilitate landlords' collection of checks (and remedies for bounced checks); (iv) an index of language diversity within each country; (v) an index of production dispersion relative to the rest of the world; (vi) an index of export dispersion from each country's exporting partners; and (vii) a similar index of import dispersion from each country's importing partners.

2. The scale problem in dynamic factor models refers to the fact that it is possible to multiply the common factors and corresponding loadings by any constant without changing their product. Furthermore, the sign of the factors and their loadings are not jointly identified, since the likelihood remains the same when both are multiplied by -1 .

3. Similar to Kose et al. $(2003,2012)$, the constant $\mathrm{c}$ is chosen based on the average innovation variance of a set of univariate autoregressions on each variable $y_{\mathrm{i}, \mathrm{t}}$.

4. Since we follow a raw-data-based clustering approach, there will always be group compositions that appear counter-intuitive as countries may share cyclic similarities even without any trade connection. 


\section{REFERENCES}

Calinski, T. and J. Harabasz (1974) A dendrite method for cluster analysis. Communications in Statistics 3, 1-27.

Ductor, L. and D. Leiva-Leon (2016) Dynamics of global business cycle interdependence. Journal of International Economics 102, 110-27.

Duda, R. O. and P. E. Hart (1973) Pattern Classification and Scene Analysis. New York, NY: Wiley.

Francis, N., M. T. Owyang and O. Savascin (2017) An endogenously clustered factor approach to international business cycles. Journal of Applied Econometrics 2017(0), 1-16.

Helbling, T., P. Berezin, M. A. Kose, M. Kumhof, D. Laxton and N. Spatafora (2007) Decoupling the train? Spillovers and cycles in the global economy. In: IMF World Economic Outlook, Chapter 4, pp. 121-160 Washington, DC: International Monetary Fund. doi: https://doi.org/10.5089/ 9781589066267.081.

Hirata, H., M. A. Kose and C. Otrok (2013) Regionalization vs. Globalization. IMF Working Paper $13 / 19$.

Kose, M. A., C. Otrok and E. Prasad (2012) Global business cycles: convergence or decoupling? International Economic Review 53(2), 511-538.

Kose, M. A., C. Otrok and C. H. Whiteman (2003) International business cycles: world, region, and country-specific factors. American Economic Review 93(4), 1216-1239.

Milligan, G. W. and M. C. Cooper (1985) An examination of procedures for determining the number of clusters in a dataset. Psychometrika 50, 159-179.

Mumtaz, H., S. Simonelli and P. Surico (2011) International comovements, business cycle and inflation: a historical perspective. Review of Economic Dynamics 14(1), 176-198.

Otrok, C. and C. H. Whiteman (1998) Bayesian leading indicators: Measuring and predicting economic conditions in Iowa. International Economic Review 39(4), 997-1014.

\section{APPENDIX A}

TABLE A1. List of countries and attribution to groups

\begin{tabular}{llccl}
\hline No. & Country & ISO code & Development level & World region \\
\hline 1 & Algeria & DZA & DE & MENA \\
2 & Argentina & ARG & EM & LAC \\
3 & Australia & AUS & IE & Oceania \\
4 & Austria & AUT & IE & Europe \\
5 & Bangladesh & BGD & DE & Asia \\
6 & Barbados & BRB & DE & LAC \\
7 & Belgium & BEL & IE & Europe \\
8 & Benin & BEN & DE & SSA \\
9 & Bolivia & BOL & DE & LAC \\
10 & Botswana & BWA & DE & SSA \\
11 & Brazil & BRA & EM & LAC \\
12 & Burkina Faso & BFA & DE & SSA \\
13 & Burundi & BDI & DE & SSA \\
14 & Cameroon & CMR & DE & SSA \\
15 & Canada & CAN & IE & NA \\
16 & Cape Verde & CPV & DE & SSA \\
17 & Chad & TCD & DE & SSA \\
18 & Chile & CHL & EM & LAC \\
\hline
\end{tabular}


TABLe A1. Continued

\begin{tabular}{|c|c|c|c|c|}
\hline No. & Country & ISO code & Development level & World region \\
\hline 19 & China & $\mathrm{CHN}$ & $\mathrm{EM}$ & Asia \\
\hline 20 & Colombia & COL & EM & LAC \\
\hline 21 & Comoros & $\mathrm{COM}$ & $\mathrm{DE}$ & SSA \\
\hline 22 & Congo - Brazzaville & $\mathrm{COG}$ & $\mathrm{DE}$ & SSA \\
\hline 23 & Congo - Kinshasa & COD & DE & SSA \\
\hline 24 & Costa Rica & CRI & $\mathrm{DE}$ & LAC \\
\hline 25 & Denmark & DNK & $\mathrm{IE}$ & Europe \\
\hline 26 & Dominican Republic & DOM & $\mathrm{DE}$ & LAC \\
\hline 27 & Ecuador & ECU & $\mathrm{DE}$ & LAC \\
\hline 28 & Egypt & EGY & EM & MENA \\
\hline 29 & El Salvador & SLV & $\mathrm{DE}$ & LAC \\
\hline 30 & Equatorial Guinea & GNQ & $\mathrm{DE}$ & SSA \\
\hline 31 & Ethiopia & ETH & $\mathrm{DE}$ & SSA \\
\hline 32 & Finland & FIN & $\mathrm{IE}$ & Europe \\
\hline 33 & France & FRA & IE & Europe \\
\hline 34 & Gabon & GAB & $\mathrm{DE}$ & SSA \\
\hline 35 & Gambia & GMB & DE & SSA \\
\hline 36 & Germany & DEU & $\mathrm{IE}$ & Europe \\
\hline 37 & Ghana & GHA & $\mathrm{DE}$ & SSA \\
\hline 38 & Greece & GRC & IE & Europe \\
\hline 39 & Guatemala & GTM & $\mathrm{DE}$ & LAC \\
\hline 40 & Guinea & GIN & $\mathrm{DE}$ & SSA \\
\hline 41 & Guinea-Bissau & GNB & $\mathrm{DE}$ & SSA \\
\hline 42 & Guyana & GUY & DE & LAC \\
\hline 43 & Haiti & HTI & $\mathrm{DE}$ & LAC \\
\hline 44 & Honduras & HND & $\mathrm{DE}$ & LAC \\
\hline 45 & Hong Kong & HKG & $\mathrm{EM}$ & Asia \\
\hline 46 & Iceland & ISL & IE & Europe \\
\hline 47 & India & IND & EM & Asia \\
\hline 48 & Indonesia & IDN & EM & Asia \\
\hline 49 & Iran & IRN & $\mathrm{DE}$ & MENA \\
\hline 50 & Ireland & IRL & IE & Europe \\
\hline 51 & Israel & ISR & EM & MENA \\
\hline 52 & Italy & ITA & IE & Europe \\
\hline 53 & Ivory Coast & CIV & $\mathrm{DE}$ & SSA \\
\hline 54 & Jamaica & JAM & DE & LAC \\
\hline 55 & Japan & JPN & IE & Asia \\
\hline 56 & Jordan & JOR & EM & MENA \\
\hline 57 & Kenya & KEN & $\mathrm{DE}$ & SSA \\
\hline 58 & Lesotho & LSO & DE & SSA \\
\hline 59 & Luxembourg & LUX & $\mathrm{IE}$ & Europe \\
\hline 60 & Madagascar & MDG & DE & SSA \\
\hline 61 & Malawi & MWI & $\mathrm{DE}$ & SSA \\
\hline 62 & Malaysia & MYS & EM & Asia \\
\hline
\end{tabular}


TABLE A1. Continued

\begin{tabular}{|c|c|c|c|c|}
\hline No. & Country & ISO code & Development level & World region \\
\hline 63 & Mali & MLI & DE & SSA \\
\hline 64 & Mauritania & MRT & DE & SSA \\
\hline 65 & Mauritius & MUS & $\mathrm{DE}$ & SSA \\
\hline 66 & Mexico & MEX & EM & NA \\
\hline 67 & Morocco & MAR & EM & MENA \\
\hline 68 & Mozambique & MOZ & $\mathrm{DE}$ & SSA \\
\hline 69 & Nepal & NPL & DE & Asia \\
\hline 70 & Netherlands & NLD & IE & Europe \\
\hline 71 & New Zealand & NZL & IE & Oceania \\
\hline 72 & Nicaragua & NIC & DE & LAC \\
\hline 73 & Niger & NER & $\mathrm{DE}$ & SSA \\
\hline 74 & Nigeria & NGA & DE & SSA \\
\hline 75 & Norway & NOR & IE & Europe \\
\hline 76 & Pakistan & PAK & EM & Asia \\
\hline 77 & Panama & PAN & $\mathrm{DE}$ & LAC \\
\hline 78 & Paraguay & PRY & $\mathrm{DE}$ & LAC \\
\hline 79 & Peru & PER & EM & LAC \\
\hline 80 & Philippines & PHL & EM & Asia \\
\hline 81 & Portugal & PRT & IE & Europe \\
\hline 82 & Rwanda & RWA & DE & SSA \\
\hline 83 & Senegal & SEN & DE & SSA \\
\hline 84 & Seychelles & SYC & $\mathrm{DE}$ & SSA \\
\hline 85 & Singapore & SGP & $\mathrm{EM}$ & Asia \\
\hline 86 & South Africa & ZAF & EM & SSA \\
\hline 87 & South Korea & KOR & EM & Asia \\
\hline 88 & Spain & ESP & IE & Europe \\
\hline 89 & Sri Lanka & LKA & $\mathrm{DE}$ & Asia \\
\hline 90 & Sweden & SWE & IE & Europe \\
\hline 91 & Switzerland & CHE & IE & Europe \\
\hline 92 & Syria & SYR & DE & MENA \\
\hline 93 & Taiwan & TWN & EM & Asia \\
\hline 94 & Tanzania & TZA & $\mathrm{DE}$ & SSA \\
\hline 95 & Thailand & THA & EM & Asia \\
\hline 96 & Togo & TGO & $\mathrm{DE}$ & SSA \\
\hline 97 & Trinidad and Tobago & TTO & $\mathrm{DE}$ & LAC \\
\hline 98 & Tunisia & TUN & $\mathrm{DE}$ & MENA \\
\hline 99 & Turkey & TUR & EM & Europe \\
\hline 100 & Uganda & UGA & $\mathrm{DE}$ & SSA \\
\hline 101 & United Kingdom & GBR & IE & Europe \\
\hline 102 & United States & USA & $\mathrm{IE}$ & $\mathrm{NA}$ \\
\hline 103 & Uruguay & URY & DE & LAC \\
\hline 104 & Venezuela & VEN & EM & LAC \\
\hline 105 & Zambia & $\mathrm{ZMB}$ & $\mathrm{DE}$ & SSA \\
\hline 106 & Zimbabwe & ZWE & DE & SSA \\
\hline
\end{tabular}


TABLE A2. Optimal number of clusters within all periods

\begin{tabular}{|c|c|c|c|c|c|c|}
\hline \multirow[b]{2}{*}{$\begin{array}{l}\text { No. of } \\
\text { clusters }\end{array}$} & \multicolumn{2}{|c|}{ Full period } & \multicolumn{2}{|c|}{ Pre-globalization period } & \multicolumn{2}{|c|}{ Globalization period } \\
\hline & $\begin{array}{c}\text { Calinski/ } \\
\text { Harabasz } \\
\text { value }\end{array}$ & $\begin{array}{l}\text { Duda-Hart } \\
\text { value }\end{array}$ & $\begin{array}{c}\text { Calinski/ } \\
\text { Harabasz } \\
\text { value }\end{array}$ & $\begin{array}{l}\text { Duda-Hart } \\
\text { value }\end{array}$ & $\begin{array}{l}\text { Calinski/ } \\
\text { Harabasz } \\
\text { value }\end{array}$ & $\begin{array}{l}\text { Duda-Hart } \\
\text { value }\end{array}$ \\
\hline 3 & 5.13 & 0.9554 & 4.38 & 0.9279 & 7.66 & 0.9066 \\
\hline 4 & 4.37 & 0.9134 & 4.07 & 0.9358 & 6.27 & 0.8192 \\
\hline 5 & 3.95 & 0.9424 & 3.86 & 0.9135 & 5.59 & 0.9468 \\
\hline 6 & 3.7 & 0.8602 & 3.73 & 0.9183 & 5.16 & 0.909 \\
\hline 7 & 3.51 & 0.8852 & 3.59 & 0.871 & 4.84 & 0.9347 \\
\hline 8 & 3.34 & 0.9128 & 3.46 & 0.8498 & 4.61 & 0.8037 \\
\hline 9 & 3.21 & 0.9165 & 3.36 & 0.8802 & 4.43 & 0.8321 \\
\hline 10 & 3.1 & 0.8946 & 3.27 & 0.8431 & 4.27 & 0.8936 \\
\hline
\end{tabular}

Note: For each time period, the superior number of clusters is highlighted when determinable by the methods used. 